\title{
Comparative Study of Two Phase Closed Thermosyphon with Different Fluids and Fill Volume Ratio
}

\author{
Yogesh S. Gandal ${ }^{1}$, Vinayak M. Kale ${ }^{2}$ \\ I(Student, Mechanical, Indira College of Engineering and Management, University of Pune, India) \\ ${ }^{2}$ (Professor, Mechanical, Indira College of Engineering and Management, University of Pune, India)
}

\begin{abstract}
In this paper an experimental study was performed to observe the effect of fill volume ratio, inclination angle and heat input supplied to understand the heat transfer characteristics of a two phase closed thermosyphon (TPCT) charged with glycol and water. For the experimentation purpose four copper TPCT's of same dimensions were designed which are filled with aqueous solution of Propylene Glycol (PG) with 50\% purity and De-ionized (DI) water with fill volume ratio of $40 \%$ and $60 \%$ and are heated with hot water in evaporator jacket from $60^{\circ} \mathrm{C}$ to $90^{\circ} \mathrm{C}$. TPCT's were also tested for the inclination of $0^{\circ}$ to $50^{\circ}$ from vertical. Temperature distributions along the length of TPCT's were noted, heat supplied to evaporator along with heat removed from condenser section were also measured. The experimental results indicate that the PG TPCT works better at higher heat inputs and its optimum inclination angle is between $20^{\circ}$ to $30^{\circ}$ and that for DI water TPCT is $10^{\circ}$ to $20^{\circ}$. Efficiencies of TPCT's were found to increase with respect to increase in heat input but are less affected with fill volume effect.
\end{abstract}

Keywords: Efficiency, Fill Volume Ratio, Heat Inputs, Inclination Angle, Two Phase Closed Thermosyphon.

\section{Introduction}

In the today's world, the scientific community is striving for effective utilization of energy. As we all know energy can neither be created nor be destroyed but it can be used effectively so that we can use it more efficiently. In an attempt of effective utilization of energy, the fluids used in the heat transfer felid hold the great potential in improving the thermal performance of the system.

At present [1], one of the most intensively discussed options is the usage of high heat carrying fluids in thermal systems. The high thermal conductivity of these fluid leads to an increased overall heat carrying capacity of thermal systems. The TPCT is one of the thermal systems considered in this work whose thermal performance is evaluated by using suitable working fluid. The TPCT is an efficient heat transfer device. It transfers a large amount of heat with very small temperature difference. It is vertically oriented with liquid pool at bottom filled under negative pressure. Heat is given to evaporator section and vapour forms rises up to the condenser section where it condense heat to the surrounding and return to the evaporator section along with the tube wall due to gravitational force. The main benefit of TPCT is that it requires no mechanical pumping furthermore which makes it inexpensive and reliable. Hence it is widely used because of its simple structure when compared to other types of heat exchangers. TPCT's [2] are being used in wide variety of applications depending upon their heat transfer ability such as solar energy utilization, geothermal conservation, die casting and injection molding, heat cooling of batteries, waste heat recovery, spacecraft application, computer electronics etc.

The heat transfer characteristics of TPCT have been investigated by many researchers for various types of fluids like water, alcohols, refrigerants etc. but most of the investigations have been limited to either low or high heat inputs [3]. S H Noie et al. [4] experimentally studied the effect of the inclination angle on the thermal performance of a TPCT with different filling ratios under normal operating conditions. A series of experiments were carried out for inclination angle range of $5^{\circ}$ to $90^{\circ}$ and filling ratios of $15 \%, 22 \%$, and $30 \%$. The results show that the TPCT has the highest thermal performance in the inclination angle range of $15^{\circ}$ to $60^{\circ}$ for $30 \%$ filling ratio. M. Karthikeyan et al. [5] determines the heat transfer coefficient of evaporator of aqueous solution of n-butanol is nearly $55 \%$ higher than that of DI water for $75^{\circ}$ inclination and $80 \mathrm{~W}$ heat input. The thermal resistance of aqueous solution of $n$-butanol is less than the de-ionized water for all the variables. A. Nuntaphan et al. [6] in his research found that the use of TEG-water mixture can extend the heat transport limitation compared with pure water and higher heat transfer is obtained compared with pure TEG at high temperature applications. R Park et al. [7] used working fluids as water-ethanol, water-ethylene glycol and water-glycerol. The results obtained shows the overall heat transfer coefficient was found to increase considerably with increasing adiabatic temperature. The thermosyphon exhibits the highest performance at the angle of about $60^{\circ}$. H. Mirshahi et al. [8] studied the effect of the heat flux, cooling water flow rate, fill ratio and extra volume on the overall performance of a partially vacuumed thermosyphon. It was seen that the thermosyphon loses its performance as the trapped gas occupies the whole condenser. Due to the existence of the trapped gas, 
increasing the heat load to the evaporator of the thermosyphon, increase of cooling water flow rate decreases the performance of the thermosyphon and to access the maximum performance of a thermosyphon when employing it for transferring heat at lower temperature, more vacuum should be established inside it.

M. Kannan et al. [9] studied the performance of a TPCT for various input heat of 0 to $1000 \mathrm{~W}$ and for various working fluids such as distilled water, ethanol, methanol and acetone. The maximum heat transport capability shows an increasing trend with increasing operating temperature. Maximum heat transport capability was found to strongly depend on the operating temperature. As the operating temperature is increased from $40^{\circ} \mathrm{C}$ to $70{ }^{\circ} \mathrm{C}$, the maximum heat transport capability is also increased from 425 to $650 \mathrm{~W}$ for water. Park et al. [10] investigated the heat transfer characteristics of two phase thermosyphon to the fill charge ratio. For small fill charge ratio the dry out limitations occurs and large fill charge ratio flooding phenomenon was observed. M Rahimi et al. [11] used water as a working fluid with $75 \%$ as fill volume and tested for 44 power inputs. The results show that it will be possible to increase the average thermal performance by $15.27 \%$ and decrease the thermal resistance by 2.35 times compared with the plain thermosyphon. $\mathrm{N}$ Zhang [12] suggests an innovation of heat-pipe system by using new working fluids, using dilute aqueous solutions of long chain alcohols to replace water as the working fluid for their unusual surface tension characteristics. Water can be replaced by a dilute aqueous solution of long-chain alcohols. Because of the unusual characteristics of surface-tension gradient with temperature of the new working fluids, the capillary limit and the boiling limit of the heat pipe systems are increased significantly, and consequently, the more large heat load can be reached. K Joudi et al. [13] studied the effect of TPCT orientation on temperature distribution at positive inclination angles ranging from $90^{\circ}$ to $22.5^{\circ}$ and for different heat pipe lengths. When the heat flux was increased from $26 \mathrm{~kW} / \mathrm{m}^{2}$ to 31.8 $\mathrm{kW} / \mathrm{m}^{2}$, the optimum inclination was $45^{\circ}$ for all different lengths of pipe. The presence of the adiabatic separator in TPCT resulted in a marked increase in heat transfer coefficient by 35\%. S Lips et al. [14] conducted experiments in a smooth inclined tube for the whole range of inclination angles. R134a at a saturation temperature of $40^{\circ} \mathrm{C}$ was used working fluid. An optimal inclination angle that leads to the highest heat transfer coefficient can be found, the increase of heat transfer can be up to $20 \%$ for an inclination angle of $75^{\circ}$. A. K. Mozumder et al. [15] design, fabricate and test a miniature heat pipe with a thermal capacity of $10 \mathrm{~W}$. Experiments were conducted for different thermal loads to assess the performance of heat pipe. The working fluids chosen were water, methanol and acetone. The temperature distribution across the heat pipe was measured. The performance of the heat pipe was quantified in terms of thermal resistance and overall heat transfer coefficient. The amount of liquid filled was varied as 35\%,55\%, $85 \%$ and $100 \%$ of the evaporator volume and the variation of the performance is observed. The fill ratio of working fluid is shown to have minimum effect on the performance of heat pipe with respect to the temperature difference when water and methanol are used as working fluids. For acetone as the working fluid, $100 \%$ fill ratio of evaporator volume shows the best result with minimum temperature difference across the evaporator and condenser. In general, fill ratios of working fluid greater than $85 \%$ of volume of evaporator show better results.

From the available literature survey it has been observed that a lot of experimental work had been done on the performance evaluation of TPCT's for fluids like alcohols and refrigerants. However, there is a scarcity of literature available which highlights on the usage of glycols and there it requires a need to gain a better insight in to the usage of such fluids in TPCT's. An investigation to see the effects of fill volume ratio is also needed. This study is carried out to see whether TPCT's charged with different fill volume of PG can enhance heat transfer and thermal performance for different inclinations and heat inputs given and results obtained are compared with the TPCT's charged same fill volume of DI water.

\section{Experimental Setup and Procedure}

Experimental setup for studying the thermal behavior of a TPCT using PG and DI water as a working fluid with varying fill volume ratio is shown in Fig. 1. For conducting the experimentation four copper TPCT's of same dimensions $(\mathrm{L}=1000 \mathrm{~mm}, \mathrm{ID}=17 \mathrm{~mm}$ and $\mathrm{OD}=19 \mathrm{~mm})$ were designed. TPCT's are charged with fill volume (the ratio of liquid volume filled to the total volume of evaporator section) of $40 \%$ and $60 \%$ with respective working fluids filled under the pressure of $10^{-2}$ Torr. The set up consists of hot water tank, evaporator jacket and condenser jacket along with measuring instruments. The hot water tank is used to heat up the water and this hot water is circulated in evaporator jacket with electric motor pump of $0.25 \mathrm{hp}$. The tank is incorporated with $1000 \mathrm{~W}$ heater to heat the cold water in the hot water tank. Evaporator jacket is a rectangular tank in which TPCT is placed. The hot water from hot water tank is allowed to enter in the evaporator jacket, which heats up the evaporative section of TPCT. Condenser jacket is made up of PVC pipe of $31.25 \mathrm{~mm}$ ID; it acts as a cooling water jacket and is used to remove the heat from the condenser section. The TPCT has the ability to transfer large amount of heat. As a result of which, a sudden rise in the wall temperature would damage the TPCT when the heat is not released correctly at the condenser end. Therefore, cooling water is dispersed first through the water jacket before supplying the heat to evaporator section. Flow rate of water is kept constant at $0.033 \mathrm{~kg} / \mathrm{sec}$ in both the sections and it is measured by the amount of the water flows over an 


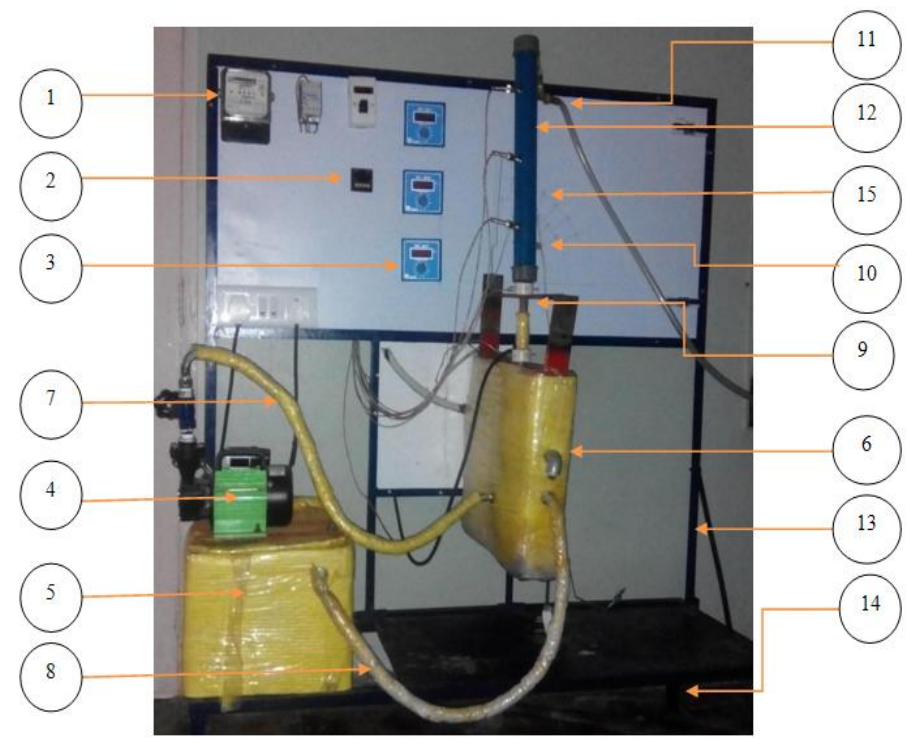

Fig: 1. Actual photograph of the experimental setup

Table 1:- Specifications of experimental setup

\begin{tabular}{|c|l|c|l|c|l|}
\hline Sr. No. & Specification & Sr. No. & Specification & Sr. No. & Specification \\
\hline 1 & Energy Meter & 2 & PID controller & 3 & Temperature Indicator \\
\hline 4 & Motor & 5 & Hot Water Tank & 6 & Evaporator Jacket \\
\hline 7 & Hot Water Inlet & 8 & Hot Water Outlet & 9 & Two Phase Closed Thermosyphon \\
\hline 10 & Condenser Inlet & 11 & Condenser Outlet & 12 & Condenser Jacket \\
\hline 13 & Main Frame & 14 & Base Stand & 15 & Inclination Marks \\
\hline
\end{tabular}

interval of time. Digital temperature indicator of 12 channels is used to measure the temperature. The surface temperature distribution of the TPCT is measured with eight copper constantan (K type) thermocouples with an accuracy of $\pm 1^{\circ} \mathrm{C}$ as shown in Fig.2.

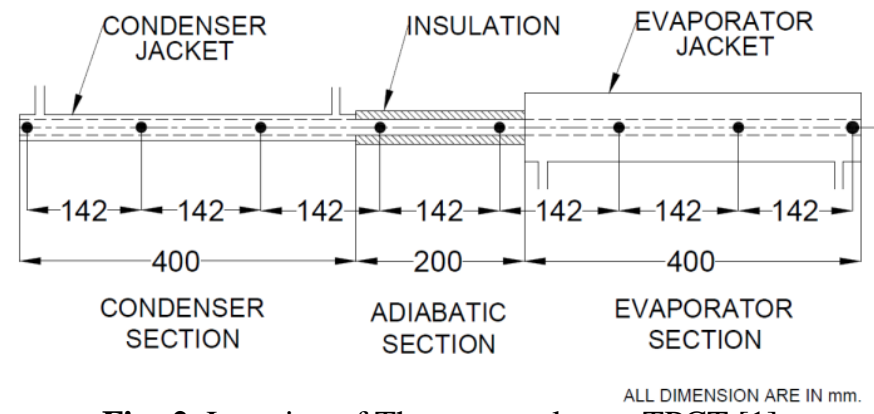

Fig: 2. Location of Thermocouples on TPCT [1]

Three thermocouples are installed on evaporator section $(\mathrm{Le}=400 \mathrm{~mm})$; three are on condenser $(\mathrm{Lc}=$ $400 \mathrm{~mm})$ and two on adiabatic section $(\mathrm{La}=200 \mathrm{~mm})$. In addition to that, two thermocouples are placed at hot water tank and condenser jacket inlet and outlet. A PID controller is used to cut off the heater by sensing evaporator jacket temperature. This thermocouple makes the assurance of desired temperature achievement in evaporator jacket. The hot water is continuously circulated from hot water tank to evaporator jacket so as to achieve uniform temperature in evaporator jacket. Glass wool insulation of $12 \mathrm{~mm}$ thickness is provided to adiabatic section, evaporator jacket, hot water tank and piping systems to avoid the heat loss to the surrounding. An energy meter is provided to measure energy consumption while conducting the experimentation. An angle holder slot is provided for giving tilt to TPCT from $0^{\circ}$ to $60^{\circ}$ inclination with a step size of $10^{\circ}$ from vertical. The experimental procedure is already explained in author's previous work [1].

\section{Statistical Data Analysis}

The [1] enormous experimental data obtained is verified statistically, in which the measure of central tendency, dispersion, asymmetry and relationship is determined. The data obtained shows closeness to mean value. Dispersion obtained shows standard deviation is between $0.4-3$ but for most readings it is close to 1 . Skewness obtained with Pearson method is between -1.2 to +1.2 but for the majority of the readings it is closed 
to 0 and for maximum reading the Karl Pearson Correlation exists positive. The probable error in the measured correlation is 0.56 .

\section{Experimental Results and Discussion}

A series of experiments were conducted to find the effect of variable parameters on the thermal performance of an inclined TPCT charged with different fluids and fill volume ratio for different heat inputs. The temperature distribution along the length of TPCT, evaporative and condenser heat transfer coefficients, heat transfer, thermal resistance and efficiency were examined.

\subsection{Temperature Distribution along the TPCT surface}

The temperature variation along the length (outer surface) of TPCT is monitored and recorded carefully with the help of thermocouples provided in the respective evaporator, adiabatic and condenser sections. From Fig 3(a-d), Fig 4(a-d) and Fig 5(a-d) we can observe the temperature variation on the PG and DI water TPCT's charged with different fill volumes, for an inclination of $0^{\circ}, 30^{\circ}$ and $50^{\circ}$ from vertical with respect to different heat inputs supplied. The heat absorption and rejection capacity of PG and DI water TPCT's are found to be varying with respect to change in variable parameters. From Fig. 3(a-d), when the TPCT's are at $0^{\circ}$ inclination, the effect of fill volume ratio is not observed clearly for most of the heat inputs.

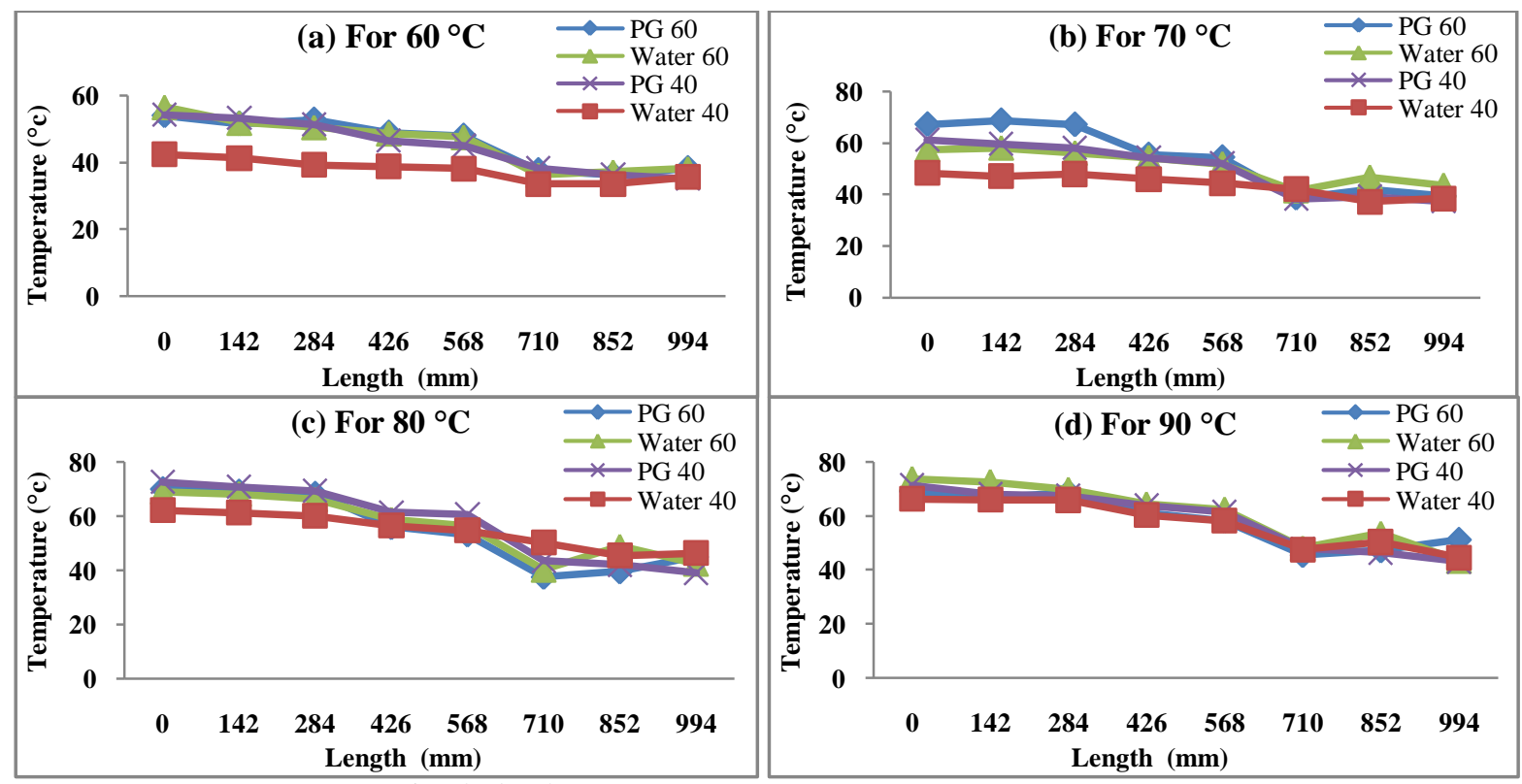

Fig: 3. (a-d) Temperature distribution for $0^{\circ}$ inclination

For heat input of $70^{\circ} \mathrm{C}$, the TPCT charged with PG $60 \%$ is having higher surface temperature and TPCT charged with water $40 \%$ is having low surface temperature when compared with other TPCT's for all heat inputs.

The change in TPCT's surface temperature distribution is observed clearly in Fig. 4(a-d), when TPCT's were tilted at $30^{\circ}$ inclination angle. The surface temperature on PG 60\% TPCT is found to be decreased with increase in a heat supplied. TPCT charged with water $60 \%$ is having high surface temperature for all heat inputs. For lower heat input of $60^{\circ} \mathrm{C}$ the $\mathrm{PG} 40 \%$ and PG60\% TPCT's show better surface temperature distribution but for higher heat input of $80^{\circ} \mathrm{C}$ and $90^{\circ} \mathrm{C}$, water $60 \%$ TPCT is having higher surface temperature distribution.
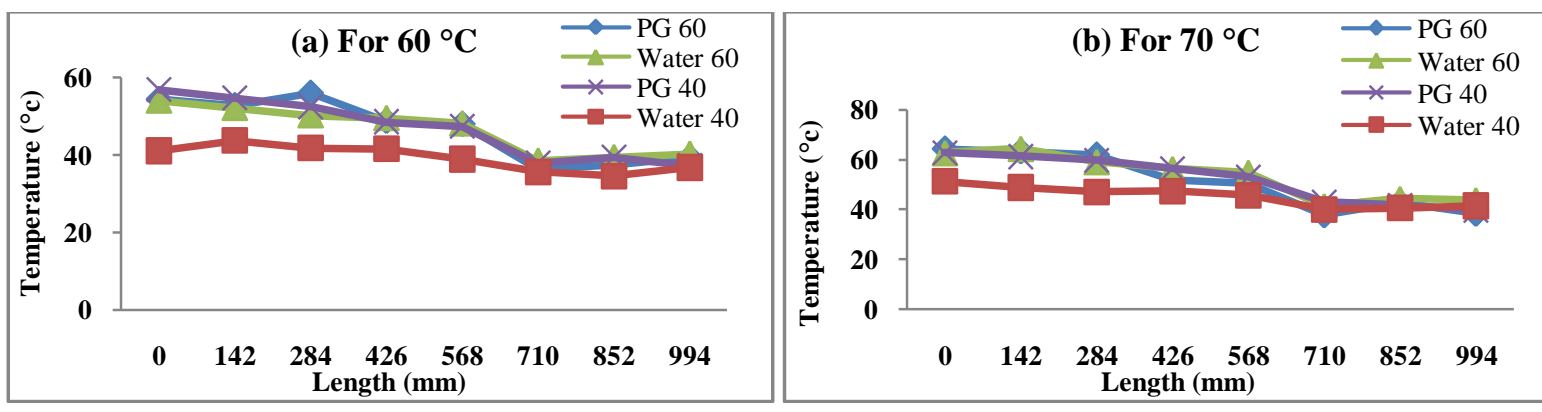


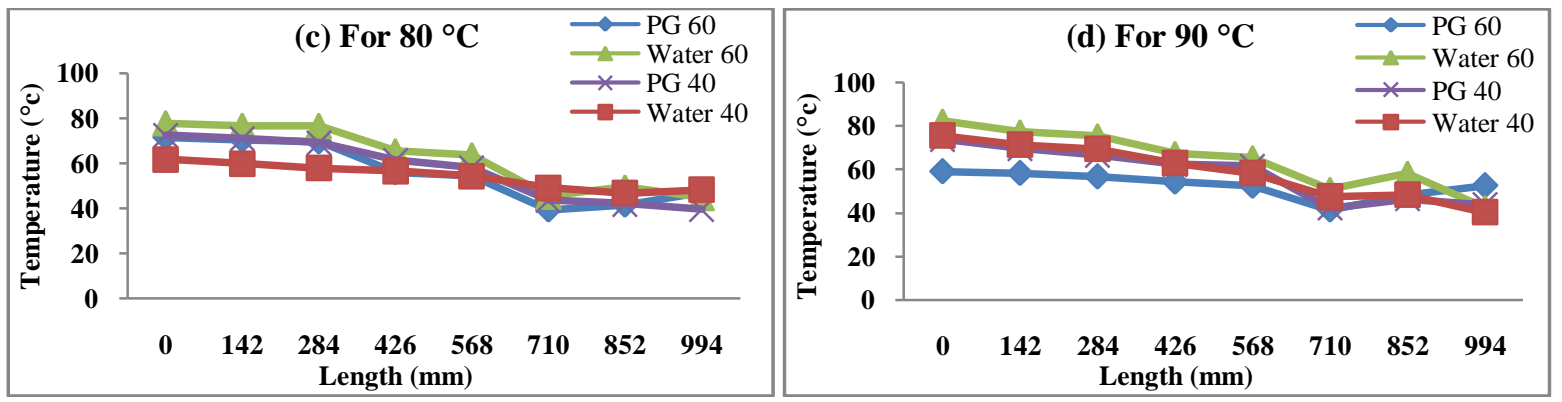

Fig: 4. (a-d) Temperature distribution for $30^{\circ}$ inclination

The effect of maximum inclination angle is shown in Fig. 5(a-d) where TPCT's were tilted at an inclination of $50^{\circ}$. TPCT charged with higher fill volume ratio shows better surface temperature distribution compared to TPCT charged with lower fill volume. The behavior of PG 40\% and 60\% TPCT's were almost same for all heat inputs. For higher heat inputs of $80^{\circ} \mathrm{C}$ and $90^{\circ} \mathrm{C}$ all TPCT's shows the similar type of temperature distribution irrespective of their fill volume ratios.

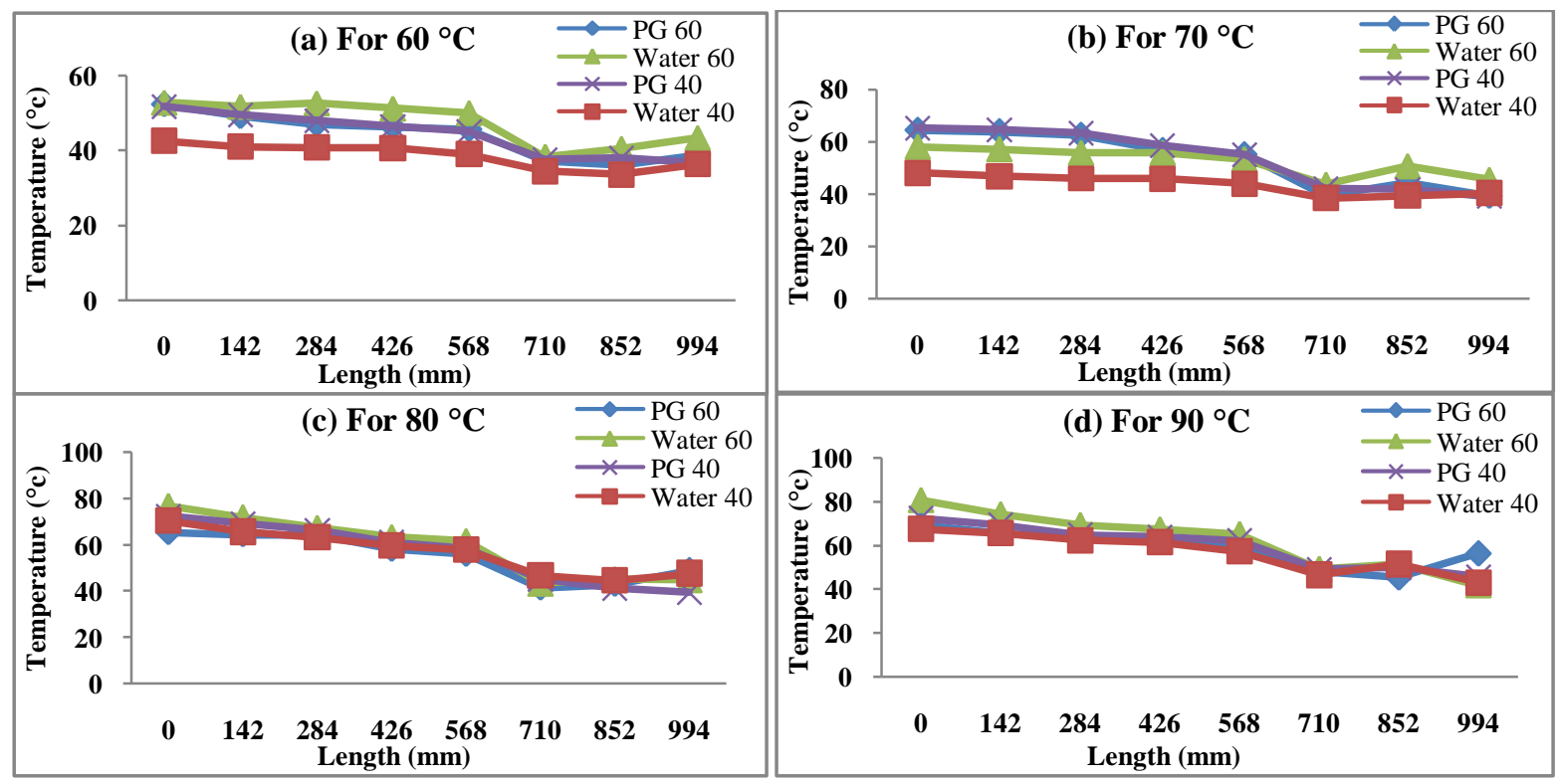

Fig: 5. (a-d) Temperature distribution for $50^{\circ}$ inclination

From the above figures we can conclude that uniform heat absorption is observed in evaporator section and the constant adiabatic temperature is observed for all the heat inputs. The effect of temperature drop in the condenser section at the entrance of cold water in condenser jacket is also noted. Insignificant increase in condenser surface temperature is noted in condenser section which is due to the accumulation of non condensable gases in this section. From the above observations it is possible to differentiate the performance of water TPCT's on the fill volume ratio but for the PG TPCT such differentiation is not possible.

Table 2:- Slope values of Temperature distribution along the length of TPCT

\begin{tabular}{|c|c|c|c|c|c|c|c|c|c|c|c|c|}
\hline Heat Input & \multicolumn{3}{|c|}{$60^{\circ} \mathrm{C}$} & \multicolumn{3}{|c|}{$70^{\circ} \mathrm{C}$} & \multicolumn{3}{|c|}{$80^{\circ} \mathrm{C}$} & \multicolumn{3}{|c|}{$90^{\circ} \mathrm{C}$} \\
\hline Inclination & $\mathbf{0}^{\circ}$ & $30^{\circ}$ & $\mathbf{5 0}^{\circ}$ & $\mathbf{0}^{\circ}$ & $3^{\circ}$ & $\mathbf{5 0}^{\circ}$ & $\mathbf{0}^{\circ}$ & $30^{\circ}$ & $\mathbf{5 0}^{\circ}$ & $\mathbf{0}^{\circ}$ & $30^{\circ}$ & $\mathbf{5 0}^{\circ}$ \\
\hline PG 60 & -2.76 & -2.86 & -2.25 & -4.92 & -4.27 & -4.11 & -4.97 & -4.85 & -3.47 & -3.52 & -1.17 & -2.86 \\
\hline Water 60 & -2.93 & -2.33 & -1.98 & -2.38 & -3.42 & -1.89 & -4.29 & -5.54 & -5.13 & -4.47 & -5.37 & -5.35 \\
\hline PG 40 & -3.08 & -3.07 & -2.32 & -3.92 & -3.72 & -4.35 & -5.40 & -5.41 & -5.20 & -4.39 & -4.79 & -3.98 \\
\hline Water 40 & -1.24 & -1.15 & -1.20 & -1.65 & -1.57 & -1.37 & -2.63 & -2.25 & -3.74 & -3.42 & -5.15 & -3.46 \\
\hline
\end{tabular}

If we try to obtain a straight line fit through the above temperature distribution curves then the following temperature gradient (slope) were observed as shown in Table 2, for the various inclination and heat inputs. The negative sign indicates the decrease in temperature with increase in a length of TPCT. For the zero slopes we can assure to have uniform heat transfer from one point to another point. From the above data we can observe the minimum slope shown by water $40 \%$ TPCT for all heat inputs and TPCT with PG60\% shows better surface temperature distribution for heat input of $90^{\circ} \mathrm{C}$. 


\subsection{Effect of the inclination angle on the heat transfer rate}

The amount of heat transferred by condenser section to the surrounding cold water in condenser jacket is calculated by considering the mass flow rate and specific heat and inlet and outlet temperature difference of water, as given in equation (1)

$$
\mathrm{Qc}=\mathrm{mc} * \mathrm{Cp} *(\mathrm{To}-\mathrm{Ti})
$$

From Fig. 6. (a-d) we can observe the heat transfer rate is get affect by the variable parameters. For lower heat input of $60^{\circ} \mathrm{C}$ and $70^{\circ} \mathrm{C}$, water $60 \%$ TPCT excel the heat transfer phenomena but for higher heat input of $80^{\circ} \mathrm{C}$ and $90^{\circ} \mathrm{C}$, PG $60 \%$ TPCT is having higher heat transfer rate for all inclination angles. For $0^{\circ}$ inclination heat transfer ability of water $40 \%$ TPCT is found to increase for all heat inputs whereas TPCT with PG $60 \%$ holds good heat transfer ability for the extreme inclination of $50^{\circ}$.

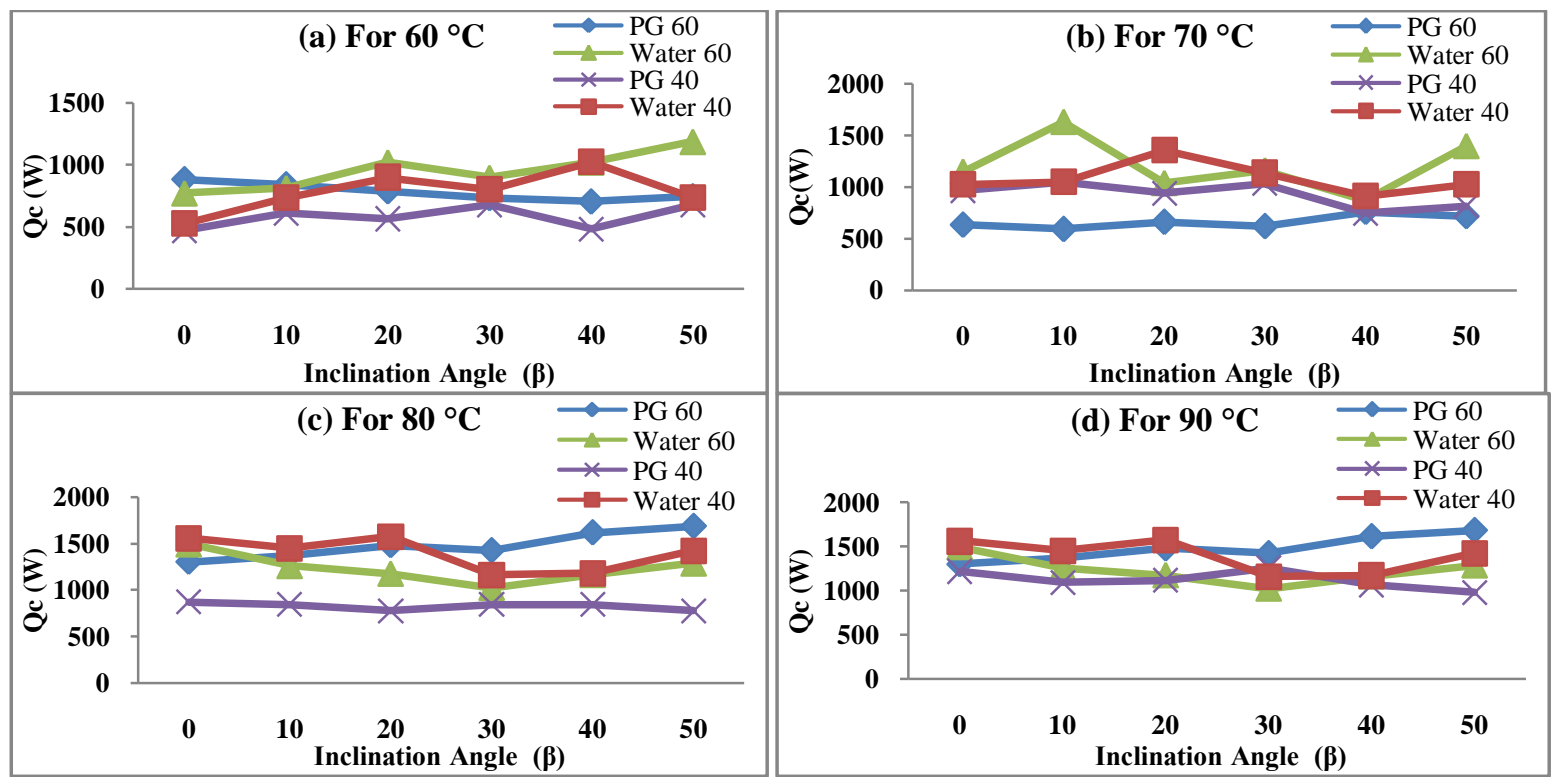

Fig: 6. (a-d) Heat transfer rate $(Q c)$ for different inclination angles $(\beta)$ at various heat inputs.

Table 3:- Slope values for heat transfer rate

\begin{tabular}{|l|c|c|c|c|}
\hline Heat Input & $\mathbf{6 0}^{\circ} \mathbf{C}$ & $\mathbf{7 0}^{\circ} \mathbf{C}$ & $\mathbf{8 0}^{\circ} \mathbf{C}$ & $\mathbf{9 0}^{\circ} \mathbf{C}$ \\
\hline PG 60 & -33.16 & 24.87 & 75.00 & 75.00 \\
\hline Water 60 & 73.42 & -26.05 & -42.24 & -42.24 \\
\hline PG 40 & 22.1 & -45.00 & -11.84 & -31.97 \\
\hline Water 40 & 51.71 & -18.16 & -55.26 & -55.26 \\
\hline
\end{tabular}

From the above slope values we found that the heat transfer rate for PG 60\% TPCT is of increasing nature which means the TPCT bears a good heat transfer capability for all inclination angles compared to other TPTC's.

\subsection{Effect of the inclination angle and on the evaporation heat transfer coefficient}

The heat absorption capacity of evaporator section of TPCT is determined by heat transfer coefficient (he) which is given by equation (2),

$$
\text { he }=\frac{\mathrm{Qe}}{\pi * \mathrm{di} * \mathrm{Le} *(\Delta \mathrm{Te}-\Delta \mathrm{Ta})}
$$

where, Qe is the rate of heat absorbed by the evaporator section of TPCT from the hot water of the evaporator jacket and is obtained from the equation (3) as mentioned below,

$$
\mathrm{Qe}=\mathrm{me} * \mathrm{Cp} *(\text { Teti }- \text { Teto })
$$

As shown in the Fig. 7. (a-d), highest heat absorption ability is observed in water $40 \%$ TPCT for $0^{\circ}$ and $50^{\circ}$ inclination angles and at all heat inputs. TPCT charged with water $60 \%$ shows increasing trend of heat absorption for all inclination and heat inputs. TPCT's charged with PG 40\% shows low heat absorbing capacity for all inclinations and heat inputs. 


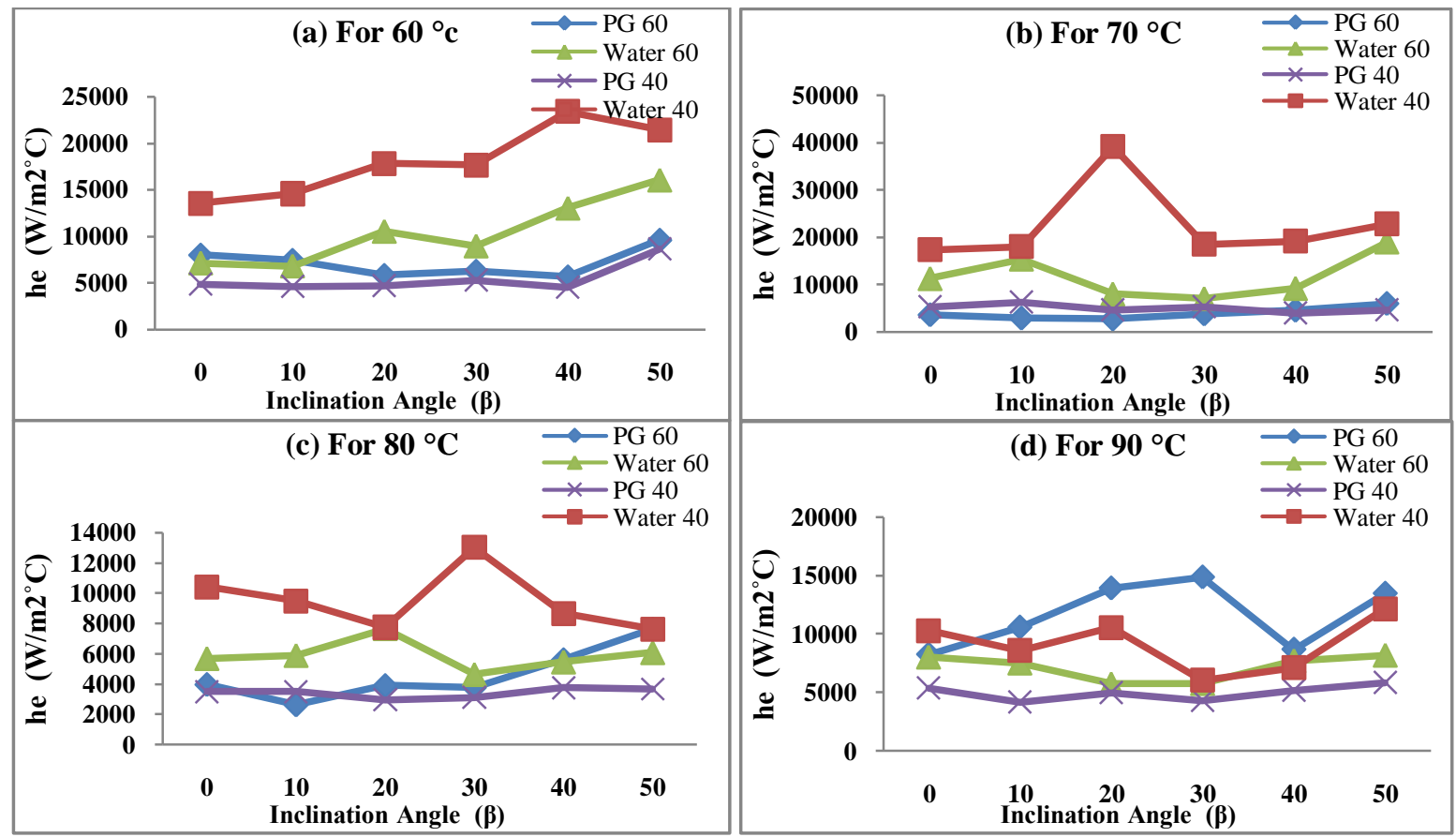

Fig: 7. (a-d) Evaporator heat transfer coefficient (he) for different inclination angles $(\beta)$ at various heat inputs.

Similar trend is observed for PG $60 \%$ TPCT up to $80^{\circ} \mathrm{C}$. For heat input of $90^{\circ} \mathrm{C}$ the PG $60 \%$ TPCT surprisingly absorbs more amount of heat from evaporator for all inclination angles. The heat transfer coefficient of evaporator for PG 60\% TPCT is nearly 66\% higher than that of DI water $60 \%$ TPCT in $30^{\circ}$ inclination and $90^{\circ} \mathrm{C}$ heat input.

Table 4:- Slope values for evaporator heat transfer coefficient

\begin{tabular}{|l|l|l|l|l|}
\hline Heat Input & $\mathbf{6 0}^{\circ} \mathbf{C}$ & $\mathbf{7 0}^{\circ} \mathbf{C}$ & $\mathbf{8 0}^{\circ} \mathbf{C}$ & $\mathbf{9 0}^{\circ} \mathbf{C}$ \\
\hline PG 60 & 89.14 & 512.6 & 772.8 & 609 \\
\hline Water 60 & 176.6 & 541.5 & -68.54 & 40.16 \\
\hline PG 40 & 551.7 & -271 & 51.87 & 135.6 \\
\hline Water 40 & 1881 & 279.8 & -317.4 & 9.565 \\
\hline
\end{tabular}

From the above slope values we found that the evaporator heat transfer coefficient for PG 60\% TPCT shows an increasing trend for all heat inputs which means the TPCT bears good heat absorption ability for all inclination angles compared to other TPTC's.

\subsection{Effect of the inclination angle on the condensation heat transfer coefficient}

The heat transfer capacity of condenser section for TPCT is determined by heat transfer coefficient (hc) which is evaluated by using equation (4)

$$
\mathrm{hc}=\frac{\mathrm{Qc}}{\pi * \mathrm{di} * \mathrm{Lc} *(\Delta \mathrm{Ta}-\Delta \mathrm{Tc})}
$$

Where, Qc is the rate of heat rejected from the condenser section to the surrounding cold water. From Fig. 8. (a-d), we can observe the similar trends of heat rejection as that of in heat absorption. TPCT charged with water $40 \%$ shows highest heat rejection for the $0^{\circ}$ and $50^{\circ}$ inclinations. TPCT's charged with PG $40 \%$ shows low heat rejection capacity for all inclinations and heat inputs. For lower heat input of $60{ }^{\circ} \mathrm{C}$ and $70{ }^{\circ} \mathrm{C}$ the water $40 \%$ TPCT shows improvement in rejection up to $30^{\circ}$ inclination beyond which this heat rejection rate gets decreased. Similar improving trend is observed for PG 60\% TPCT for higher heat input of $80^{\circ} \mathrm{C}$ for all inclination angle but for $90^{\circ} \mathrm{C}$ this improvement trend breaks ahead of $30^{\circ}$. It is also observed that the heat transfer coefficient of condenser section is slightly lower than that of the heat transfer coefficient of evaporator section for all the heat inputs and inclination angle. This is due to accumulation of non condensable gases in the condenser section of the TPCT which resists the heat transfer from vapor to TPCT wall. The heat transfer coefficient of condenser of PG 60\% TPCT is nearly $70 \%$ higher than that of DI Water $60 \%$ TPCT for $30^{\circ}$ inclination at $90{ }^{\circ} \mathrm{C}$ heat input. 


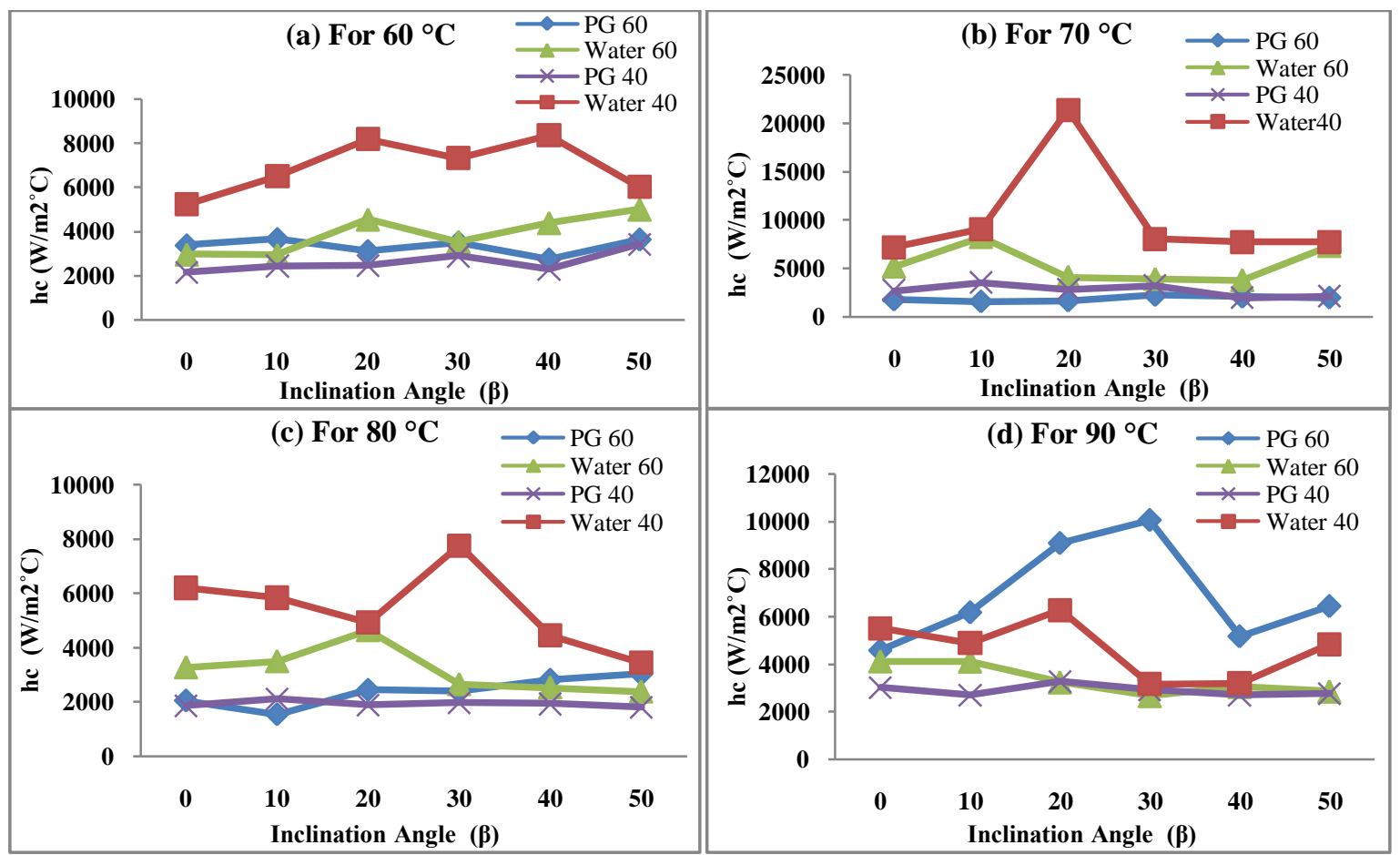

Fig: 7. (a-d) Condenser heat transfer coefficient (hc) for different inclination angles $(\beta)$ at various heat inputs.

Table 5:- Slope values for condenser heat transfer coefficient

\begin{tabular}{|l|c|c|c|c|}
\hline Heat Input & $\mathbf{6 0}^{\circ} \mathbf{C}$ & $\mathbf{7 0}^{\circ} \mathbf{C}$ & $\mathbf{8 0}^{\circ} \mathbf{C}$ & $\mathbf{9 0}^{\circ} \mathbf{C}$ \\
\hline PG 60 & -29.89 & 88.66 & 249.6 & 207.3 \\
\hline Water 60 & 387.2 & -85.26 & -267.2 & -287.8 \\
\hline PG 40 & 179.2 & -208.2 & -22.41 & -43.98 \\
\hline Water 40 & 246.7 & -420 & -432.7 & -328.2 \\
\hline
\end{tabular}

From the above slope values we found that the PG 60\% TPCT shows an improving trend of heat transfer coefficient for all heat inputs along the all inclinations which means the PG TPCT holds good heat rejection ability angles compared to other TPTC's.

\subsection{Effect of the inclination angle on total thermal resistance of the TPCT}

The thermal resistance of the TPCT is the average temperature difference between the evaporator and condenser to the amount of heat absorbed by TPCT which is calculated by expression (5),

$$
\mathrm{R}=\frac{(\Delta \mathrm{Te}-\Delta \mathrm{Tc})}{\mathrm{Qe}}
$$

It is the resistance to the flow of heat from one point to the other, for better heat transfer the thermal resistance has to be on a lower side. An observation can be drawn from Fig. 9 (a-d), the water 40\% TPCT shows a low thermal resistance up to $80{ }^{\circ} \mathrm{C}$ heat input for all inclination angles and for $90{ }^{\circ} \mathrm{C}$ the PG $60 \%$ TPCT have the minimum thermal resistance. The PG $40 \%$ TPCT shows a higher resistance to all heat inputs. For maximum inclination of $50^{\circ}$ for all heat inputs the thermal resistance is found to be decreased compared to $0^{\circ}$ inclination.

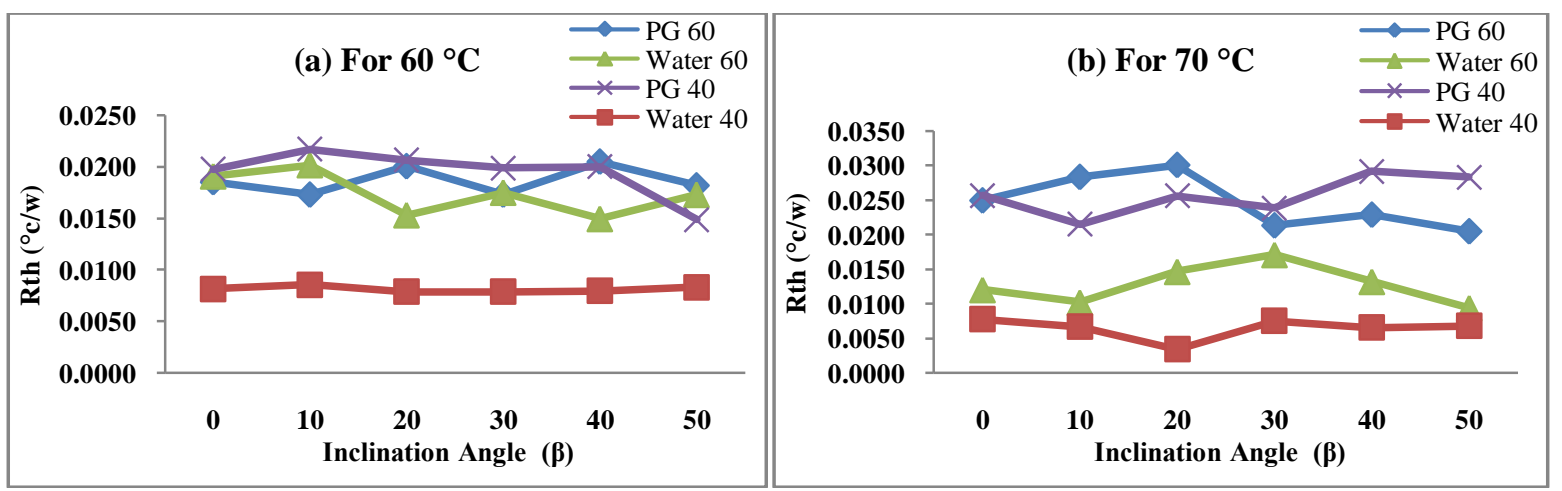




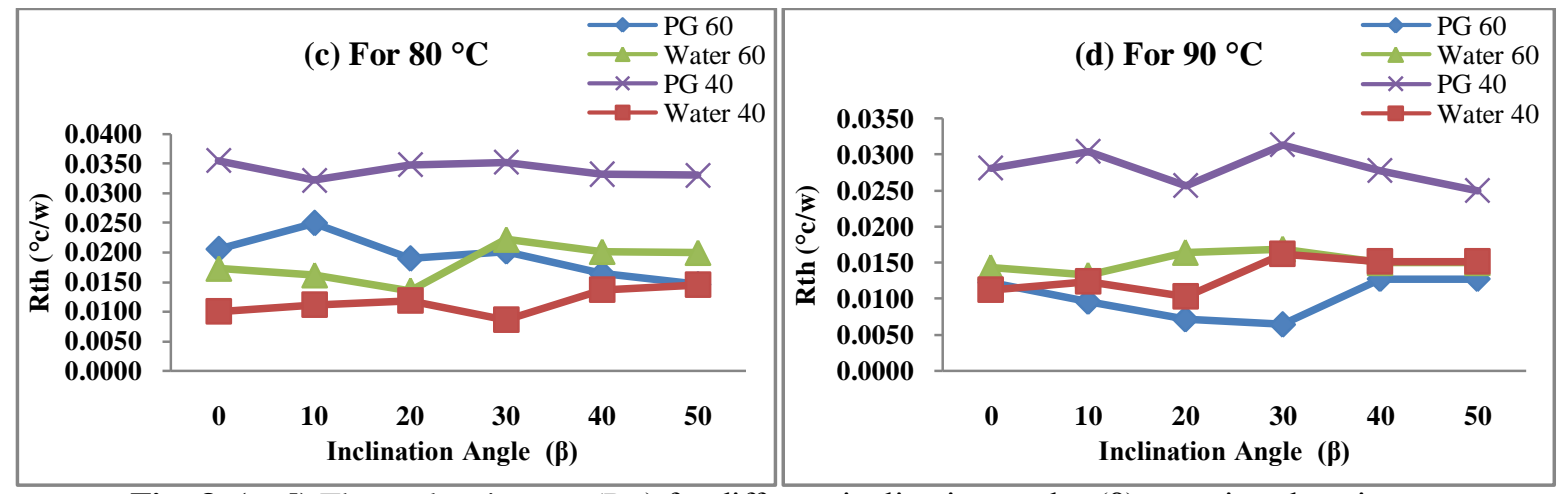

Fig: 8. (a-d) Thermal resistance $\left(\mathrm{R}_{\mathrm{th}}\right)$ for different inclination angles $(\beta)$ at various heat inputs

Thermal resistance of all TPCT is found to be decreased for all inclination angles for higher heat input of $90^{\circ} \mathrm{C}$. For all variables the majority of the readings for slope values for the thermal resistance are coming to zero which means the value of thermal resistance is unaffected with inclination effect.

\subsection{Effect of the inclination angle on Efficiency}

The efficency of TPCT is calculated as the ratio of amount of heat rejected (hc) by the condenser to the amount of heat absorbed (he) by the evaoporator section of the TPCT.

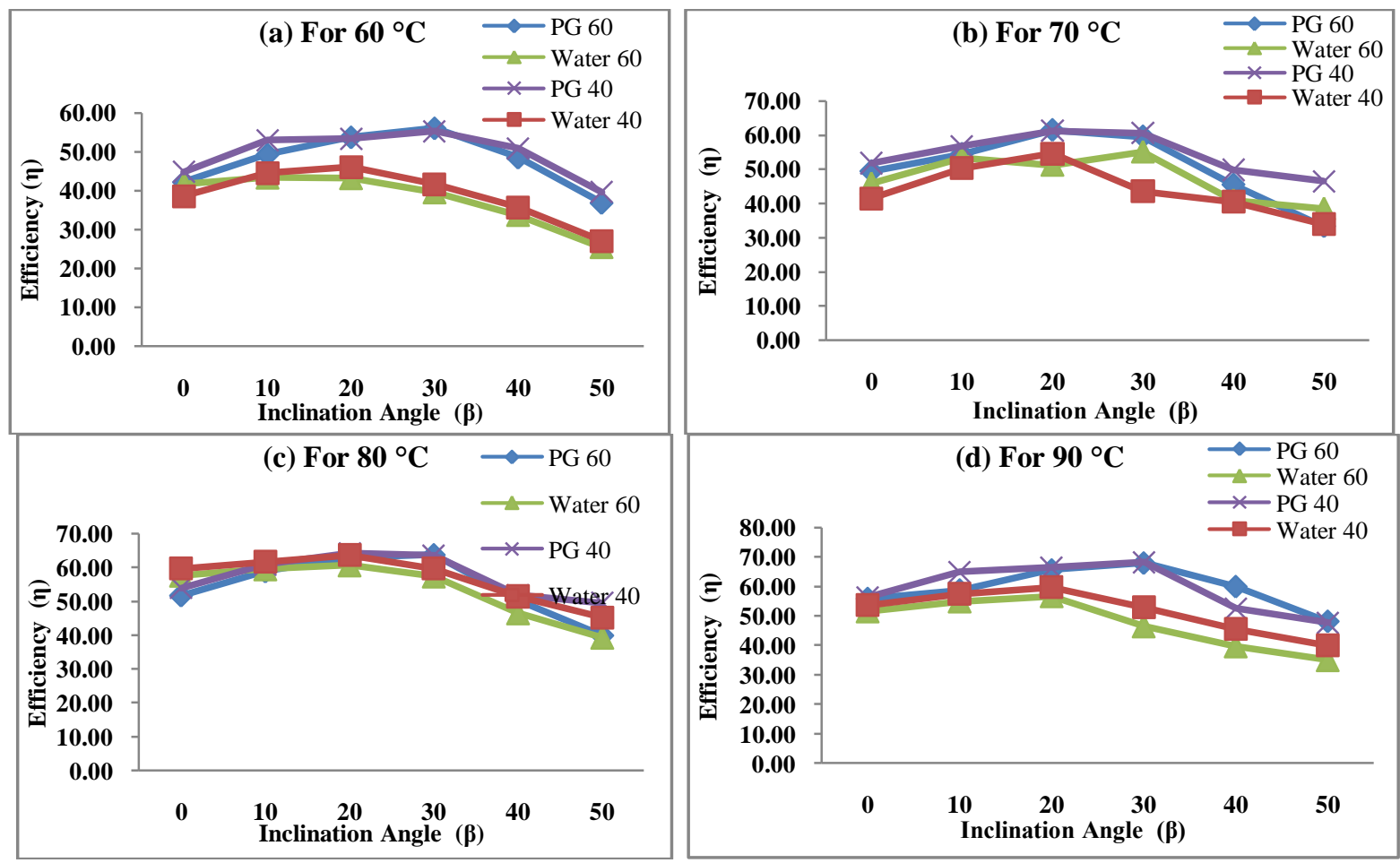

Fig: 9. (a-d) Efficiency $(\eta)$ of TPCT for different inclination angles $(\beta)$ at various heat inputs

From the following plots we can observe the efficiency of PG TPCT is higher than the DI water TPCT for all heat inputs over all inclination angles. From Fig. 10 (a-d), for all the heat inputs the efficiency of vertical TPCT's for all fill volume ratio remains same but with the increase in the inclination angles the efficency of PG TPCT remains on higher side compared to DI water TPCT. Between $20^{\circ}$ to $30^{\circ}$ of inclination PG TPCT's with different fill volume ratio have maximum efficiency of $67 \%$ for all heat inputs \& at $20^{\circ}$ water TPCT is having maximum efficiency of $64 \%$. The effect of fill volume ratio on the efficiency of TPCT is observed to some extent.

From the slope values of efficiency the following observations can be made. The lower sope values are obtained by $\mathrm{PG}$ TPCT's. For $60^{\circ} \mathrm{C}$ and $90^{\circ} \mathrm{C}$ the $\mathrm{PG} 60 \%$ having lower slope value but for $70^{\circ} \mathrm{C}$ and $80^{\circ}$ $\mathrm{C}$ it is the PG $40 \%$ TPCT with lower slope values for all incilation angles. Based on above remark we can say that PG TPCT works better than water TPCT. 
Table 6:- Slope values for efficiency of TPCT

\begin{tabular}{|c|c|c|c|c|}
\hline Heat Input & $\mathbf{6 0}^{\circ} \mathbf{C}$ & $\mathbf{7 0}^{\circ} \mathbf{C}$ & $\mathbf{8 0}^{\circ} \mathbf{C}$ & $\mathbf{9 0}^{\circ} \mathbf{C}$ \\
\hline PG 60 & -0.77 & -3.12 & -2.83 & -0.94 \\
\hline Water 60 & -3.25 & -2.01 & -3.83 & -3.93 \\
\hline PG 40 & -0.86 & -1.37 & -1.41 & -2.26 \\
\hline Water 40 & -2.54 & -2.24 & -3.05 & -3.16 \\
\hline
\end{tabular}

\section{Conclusion}

This following study were conducted with an aim of investigating whether the use of Propylene Glycol in TPCT can enhance heat transfer characteristics compared to DI water TPCT's. The PG TPCT's were tested for two fill volume ratios, four heat inputs and six inclination angles and the results obtained are compared with DI water TPCT based on which following conclusion can be made. The temperature distribution along the length of TPCT surface is found to be varying with change in inclination angle for all heat inputs. The PG TPCT shows better temperature distribution compared to water TPCT for $50^{\circ}$ inclination. For $0^{\circ}$ inclination heat transfer ability of water $40 \%$ TPCT is found to increase for all heat inputs whereas TPCT with PG $60 \%$ holds good heat transfer ability for the extreme inclination of $50^{\circ}$. The evaporative heat transfer coefficient of PG $60 \%$ TPCT is nearly $66 \%$ higher than that of DI water $60 \%$ TPCT for $30^{\circ}$ inclination and $90^{\circ} \mathrm{C}$ heat input. The heat transfer coefficient of condenser section is slightly lower than that of the heat transfer coefficient of evaporator section for all the heat inputs and inclination angle. TPCT charged with water $40 \%$ shows a lower thermal resistance for all inclination angle compared to PG TPCT charged with different fill volume. The efficiency of PG TPCT found to be higher than the water TPCT. Maximum efficiency of $68 \%$ is observed for PG TPCT between $20^{\circ}$ to $30^{\circ}$ of inclination for $90^{\circ} \mathrm{C}$ heat input and for water TPCT it is up to $63 \%$ for $80^{\circ} \mathrm{C}$ heat input.For the given heat input insignificant effect of fill volume ratio is observed on the TPCTs performance.

\section{Future Work}

Every research work will always have a definite scope of further research. It is an enduring process of research that the present status of the system can be changed by having certain amendment, enhancement, improvement, etc. The PG TPCT can be investigated for its $100 \%$ purity along with this it is possible to investigate its performance for higher heat inputs. Alteration with material of TPCT is also possible. Further part of this project work will be making analysis with the help of computational solver.

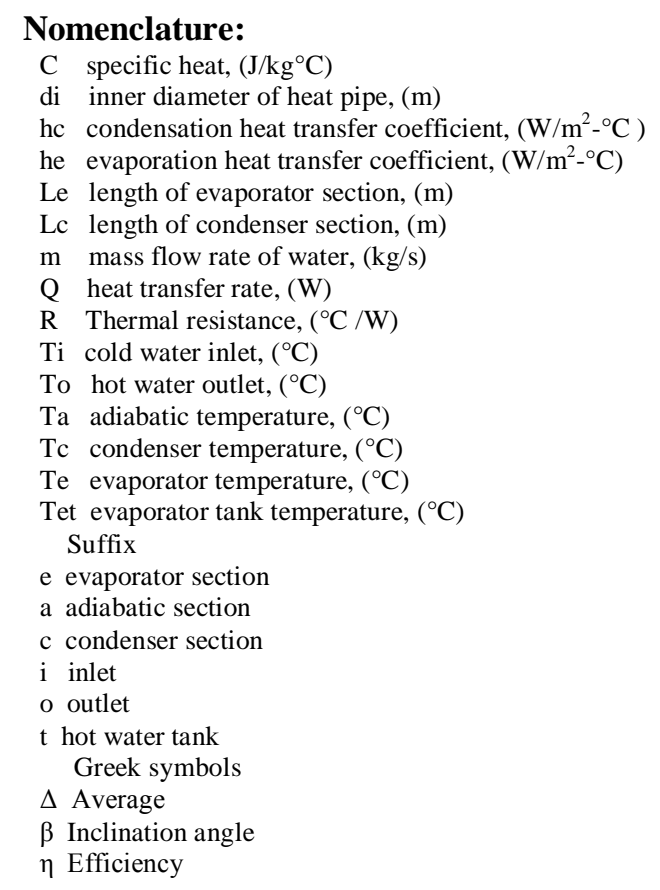




\section{References}

[1] Yogesh S. Gandal and Vinayak M. Kale, Experimental investigation of two phase closed thermosyphon using propylene glycol as a working fluid, International Journal of Engineering Research \& Technology, 3(8), 2014, 479-485.

[2] S. Seshan and D. Vijaylaxmi, Heat Pipes - Concepts, Materials and Applications, Energy Conservation and Management, 26(1), 1986, 1-9.

[3] H. Li, A. Akbarzadeh and P Johnson, The thermal characteristics of a closed two-phase thermosyphon at low temperature difference, Heat Recovery Systems \& CHP, 11(6), 1991, 533-540.

[4] S. H. Noie, M. R. Sarmasti Emami, M. Khoshnoodi, Effect of inclination angle and filling ratio on thermal performance of a twophase closed thermosyphon under normal operating conditions, International Journal of Heat Transfer Engineering, 28(4), 2010, $365-371$.

[5] M. Karthikeyan, S. Vaidyanathan, B. Sivaraman, Heat transfer analysis of two phase closed thermosyphon using aqueous solution of n-butanol, International Journal of Engineering and Technology, 3(6), 2013, 661-667.

[6] A. Nuntaphan, J. Tiansuwan, T. Kiatsiriroat, Enhancement of heat transport in thermosyphon air preheater at high temperature with binary working fluid: A case study of TEG-water, Applied Thermal Engineering 22, 2002, 251-266.

[7] R Park, Two phase closed thermosyphon with two fluid mixtures, doctoral dissertation, University of Ottawa, Canada, 1992.

[8] H. Mirshahi, M. Rahimi, Experimental study on the effect of heat loads, fill ratio and extra volume on performance of a partialvacuumed thermosyphon, Iranian Journal of Chemical Engineering, 6(4), 2009, 15-26.

[9] M. Kannan and E. Natarajan, Thermal performance of a two-phase closed thermosyphon for waste heat recovery system, Journal of Applied Sciences, 10 (5), 2010, 413-418.

[10] Park, Y. J., Kang, H. K., Kim, C.J., Heat transfer characteristics of two-phase closed thermosyphon to the fill charge ratio, International Journal of Heat and Mass Transfer, 45, 2002, 4655-4661.

[11] M. Rahimi, K. Asgary, Simin Jesri, Thermal characteristics of a resurfaced condenser and evaporator closed two-phase thermosyphon, International Communications in Heat and Mass Transfer, 37, 2010, 703-710.

[12] N. Zhang, Innovative heat pipe systems using a new working fluid, Int. Comm. Heat \& Mass Transfer, 28 (8), $2001,1025-1033$.

[13] Khalid A. Joudi, A.M. Witwit, Improvements of gravity assisted wickless heat pipes, Energy Conversion \& Management, 41, 2000, 2041- 2061.

[14] Stéphane Lips, Josua P. Meyer, Experimental study of convective condensation in an inclined smooth tube. Part I: Inclination effect on flow pattern and heat transfer coefficient, International Journal of Heat and Mass Transfer, 55, 2012, 395-404.

[15] A. K. Mozumder, A. F. Akon, M. S. H. Chowdhury and S. C. Banik, Performance of heat pipe for different working fluids and fill ratios, Journal of Mechanical Engineering, 41(2), 2010, $96-102$. 